\title{
A paisagem como dimensão simbólica do espaço: o mito e a obra de arte*
}

\author{
LEONARdo H. G. FÍGOLI**
}

\begin{abstract}
Resumo: A paisagem é um modo de representação da natureza; é uma imagem cultural do espaço geográfico. Como símbolo espacial de um imaginário, a paisagem aponta para um sentido, mais que ao entorno. No caso estudado, as letras e as artes plásticas foram essenciais na construção das representações do espaço regional e na elaboração das grandes imagens míticas. Esse sistema de representações tem a paisagem como símbolo dominante e constitui o fundamento de uma ideologia regional, bem como o da auto-imagem dos seus habitantes. Neste trabalho, procuramos compreender o significado da moderna produção artística de Alberto da Veiga Guignard. Focalizamos sua obra sobre a paisagem regional de Minas Gerais não como simples "visão de mundo", mas como universo plástico articulado ao imaginário social, simultaneamente renovador e ordenador de valores míticos, porque a autêntica obra de arte é aquela que consegue ressuscitar ou restaurar o mito.
\end{abstract}

Palavras-chave: arte e imaginário; paisagem, arte e identidade; identidade regional, paisagem e simbolismo.

\section{Introdução}

O tema deste trabalho é a paisagem como uma das formas simbólicas do espaço, portanto, como uma forma cultural. Buscamos compreender o lugar da paisagem em um contexto cultural regional: a região de Minas Gerais. Atribuímos importante papel aos discursos figurativos, tais como a literatura e a pintura, que ao longo da história modelaram o imaginário social sobre a paisagem regional. Na pintura, o gênero paisagístico local é de longa data, mas alcançou a mais complexa elaboração com a pintura modernista de Alberto da Veiga Guignard. Anali-

\footnotetext{
* Trabalho apresentado no XIII Ciclo de Estudos sobre o Imaginário, em outubro de 2004, em Recife (PE).Versões preliminares foram apresentadas na XXIV Reunião da Associação Brasileira de Antropologia (ABA), em Recife (PE), em junho de 2004, e no seminário Cultura Contemporânea: Imbricações e Hibridismos, na Unesp, em Araraquara, em outubro de 2004.

** Professor associado do Departamento de Sociologia e Antropologia (SOA), da Universidade Federal de Minas Gerais (UFMG).
}

sar uma obra de arte exige, antes de mais nada, escapar do falso problema que a reduz ora como expressão do mundo psíquico do autor, ora como manifestação do mundo social. Para ir além das interpretações biográficas ou contextualistas, centramos a atenção em três grandes questões: o tema, o estilo e o regime da imagem da obra. Ao analisarmos a chamada "fase mineira" da produção artística de Guignard, propomos-nos a captar o imaginário expresso simbolicamente na e pela obra de arte, como articuladora de valores míticos (Durand, 1993, p. 136).

\section{A paisagem: dimensão simbólica do espaço}

A paisagem pode ser definida como uma área composta por associação de formas, ao mesmo tempo físicas e culturais. Ao contrário do olhar geográfico, que deixa escapar todo o significado da paisagem humana ao reduzi-la a forças naturais, a paisagem pode ser vista como 
expressão humana intencional, formada por muitas camadas de significação (Lobato Corrêa e Rosendahl, 1998, p. 9 e passim).

A paisagem é muito mais que o simples espaço exterior ao homem. Desde o Renascimento, foi entendida como criação racionalmente ordenada, ligada a uma maneira de harmonizar o mundo (Lobato Corrêa e Rosendahl, 1998). Mais que um território que a natureza apresenta ao observador, é produto de uma maneira de ver o espaço externo, um cenário que supõe um espectador, um olhar particular sobre o mundo externo. Em suma, a paisagem é um relato, um desenho, uma representação. Território recortado por uma "janela", apreciado desde um ponto de vista singular, freqüentemente esse ponto de vista é artístico, envolvendo uma série de técnicas particulares desenvolvidas para representá-lo e transformá-lo em imagem cultural pela atribuição de um significado.

A paisagem é, portanto, um signo (dizível) integrante de um imaginário social (geralmente regional) que aponta para um sentido (indizível), mais que ao objeto sensível que lhe serve de referência: paese feito paisagem. No horizonte de alguns imaginários sociais, a paisagem tem feito do entorno exterior e visível a chave para a compreensão do sentido da vida humana (Fígoli, 2006, p. 439). No caso em estudo, a paisagem de Minas Gerais tem constituído a pedra angular de um longo e complexo sistema simbólico ou ideologia regional, na qual se assenta a auto-imagem de seus habitantes. Ricamente burilada a "pena e pincel", por extensa e obsessiva atividade discursiva imagético-figurativa, a paisagem mineira constitui uma das grandes imagens míticas do imaginário regionalista.

\section{Um mitema: a pintura paisagística}

É consenso entre os historiadores que a origem dos mitos da "mineiridade" remonta ao século XVIII. Se a singularidade topográfica mineira foi, de início, considerada estranha para os padrões literários europeus vigentes, aos poucos foi incorporada à literatura, evidência da constituição de uma nova sensibilidade sobre o entorno (Sampaio, 1977, p. 9).

A visão romântica da natureza do século XVIII se faz sentir na pintura do período, que incorpora a paisagem como suporte da narrativa e da composição das cenas, como ilustram as igrejas mineiras (Sampaio, 1977, p. 9). É à sombra do naturalismo rousseauniano que a pintura de paisagens afirma-se como gênero pictórico, em oposição à artificialidade da civilização moderna, registro do surgimento de uma nova percepção do espaço que não está desvinculada da expressão de sentimentos nacionalistas.

A região, no século seguinte, passa por profundas mudanças. Após o florescimento das cidades do ciclo do ouro e do diamante, sobrevieram a pobreza e a estagnação. Uma nova vocação econômica centrada nas atividades rurais modifica a relação do homem com o entorno, e com ela o nascimento de novas cidades. Sob a influência da Academia Imperial de Belas Artes, a arte mineira produz as primeiras pinturas de paisagens consideradas como gênero independente. Alguns artistas abandonam as cenas acadêmicas para mergulhar nas paisagens locais, que ganham em veracidade ao serem conectadas às narrativas da Inconfidência, constituindo o fundo das lutas pela independência (Sampaio, 1977, p. 9).

O século XX é de intensa renovação nas artes. Novas linguagens e tendências artísticas se espalham, no começo do século, na Europa e nos Estados Unidos. Enquanto isso, Minas permanecia completamente alheia a esses movimentos. Nas primeiras décadas, firmam-se os nomes de alguns artistas paisagistas. Em 1918, chega a Belo Horizonte o fluminense Aníbal Pinto Mattos, que inicia um significativo movimento cultural, com a criação da Sociedade Mineira de Belas Artes e do Salão de Belas Artes. Dizia-se que Mattos era um apaixonado intérprete da natureza de Minas: "a terra mineira surge de suas telas transfigurada e idealizada pela sua paleta de pintor poeta" (Sampaio, 1977, p. 18).

É sintomático que a Semana de Arte Moderna, de 1922, não tenha repercutido imediatamente na arte mineira. ${ }^{1}$ Longe de manterem a estreita relação e a mútua influência que expe-

\footnotetext{
1. Os jovens escritores e poetas de Belo Horizonte e Cataguases, desde o início, sintonizaram as idéias revolucionárias e demolidoras do modernismo, procurando a saída do estágio parnasiano e simbolista. Sobre a estreita relação que o grupo da 'alegre e paradoxal' revista Verde, de Cataguases, mantinha com o movimento modernista, assim se refere Mário
} 
rimentavam os poetas modernistas paulistas e mineiros nas décadas de 1920 e $1930,{ }^{2}$ os pintores mineiros se mantêm fiéis à concepção da arte que visava mais à reprodução naturalista, à documentação, do que à interpretação livre da natureza; apegados à ordem antiga, à força da tradição, preferiam pintar suas telas com imagens dos panoramas coloniais.

Arrefecida a efervescência dos anos 20, a arte moderna começa, na década seguinte, a sedimentar-se no Brasil. Em Minas, grandes vocações literárias modernistas serão importante expressão da mineiridade ${ }^{3}$ o que contribui para uma nova forma de olhar o espaço regional. $\mathrm{Na}$ pintura, a paisagem é o gênero pictórico que melhor se integra ao espírito das classes que consomem arte. No período, os artistas voltavam-se para as cidades coloniais do ciclo do ouro e, na sua busca de fixar as raízes locais, descobriam os povoados e as matas, as montanhas, os rios e os homens habitantes desses mundos perdidos (Sampaio, 1977, p. 20).

Na década de 1940, inicia-se uma grande mudança no campo artístico, a reboque das que se faziam sentir no terreno político e econômico. Sendo prefeito Juscelino Kubitschek, Belo Horizonte será objeto de grande mudança arquitetônica, com a implantação do conjunto urbanístico da Pampulha, concebido por Oscar Niemeyer e Roberto Burle Marx ${ }^{4}$ primeira paisa-

de Andrade (1929): "Não é possível a gente conceber a formação de um espírito sem influências, fruto unicamente de Cataguases. Existe influência de tal escritor paulista sobre os moços de Cataguases, como existe influência dos moços de Cataguases sobre esse escritor paulista. É maior que imaginam, muito maior".

2. Como no século XIX Minas tinha recebido um grupo de viajantes estrangeiros, que documentou a Minas do período, em 1924 um importante grupo de viajantes ilustres veio conhecer ou revisitar as sociedades históricas. O grupo formado por Mário de Andrade, Oswald de Andrade, Tarsila do Amaral, entre outros, empreende a redescoberta do Brasil, dando inicio à reavaliação da arte do século XVIII em Minas, redescoberta que alimentará não só os poemas de Mário, Oswald e Cendrars, como os desenhos que Tarsila fez para registrar a viagem e as pinturas que posteriormente produziu. Se os artistas plásticos mineiros não se beneficiaram diretamente da visita, os escritores tiveram a oportunidade de estreitar o relacionamento com eles (Sampaio, 1977, p. 19).

3. Como Emílio Moura e Abgar Renault, Carlos Drummond de Andrade lança, em 1930, seu primeiro livro, Alguma poesia.

4. Utilizando-se essencialmente da vegetação própria da região, a paisagem nova integra formas naturais, arquitetura e a paisagem circundante. A obra mais representativa do gem urbana moderna de Minas e marco da arquitetura moderna nacional. A construção da Pampulha propicia, com a presença de Candido Portinari, a idéia de criar uma escola de arte nos moldes modernos e que, por sugestão dos modernistas, ficará a cargo do pintor Alberto da Veiga Guignard.

\section{O estilo: acadêmicos e modernos}

Aceita a proposta de Kubitschek, Guignard deixa o Rio de Janeiro e vem a Belo Horizonte em 1944 para implantar um curso de pintura e desenho. Sem ser modernista radical, promove a abertura das artes plásticas locais para a contemporaneidade. Nesse mesmo ano, tem lugar a I Exposição de Arte Moderna em Belo Horizonte, organizada pela prefeitura no intuito de promover as novas tendências pictóricas, reunindo obras dos mais importantes artistas modernos do país, as quais apresentam um novo olhar sobre o território, as tradições e sua gente, para o campo artístico local em plena efervescência.

Essas expressões plásticas modernas não foram rapidamente compreendidas. $\mathrm{O}$ momento era de certa tensão e de ecletismo. ${ }^{5}$ Nesse complexo ambiente intelectual e artístico, ${ }^{6}$ a Escola de Guignard desenvolve-se em franca rivalidade com a de Aníbal Mattos, que tinha aglutinado as figuras mais destacadas do academicismo,

conjunto, a Igreja de São Francisco, é a primeira obra moderna em que a paisagem minera, ao repetir a forma de suas montanhas, é explicitamente abordada (Sampaio, 1977, p. 21).

5. Em meio à tradição, herdada da antiga Ouro Preto, e a modernidade, imposta por sua própria condição de cidade planejada, a nova capital carece, desde sua inauguração, de uma imagem. Sua face eclética, ainda que de remanência oitocentista, tem uma aura moderna, e a busca de uma identidade com o moderno é o que dará a tônica do desenvolvimento da cidade (Sampaio, 1977, p.17).

6. Os principais expoentes do núcleo modernista, que tiveram ativa participação na vida intelectual mineira, eram: Carlos Drummond de Andrade, Emílio Moura, Pedro Nava, Martins de Almeida e João Alphonsus. Vanda Klabin, em artigo publicado a respeito do ambiente cultural na época, comenta o seguinte: "O ambiente cultural mineiro já revelava, desde a década de 20 , uma série de inquietações em torno da renovação artística, com o surgimento de uma geração de intelectuais que seriam os novos agentes da cultura. Estas novas formulações apontam para novas maneiras de ver e agir, que começam lentamente a entrar em ebulição na ainda muito restrita e provinciana capital mineira" (apud Zílio, 1983, p. 41). 
tornando-se um dos maiores focos de resistência ao avanço das tendências modernistas.

Em Minas, desde os anos 20, era intenso o confronto entre os modernos e os conservadores. Se, no âmbito da literatura, o movimento modernista não encontrou sérias resistências para penetrar no ambiente cultural mineiro, no terreno das artes plásticas o confronto com as estruturas acadêmicas vai se dar tardiamente e se caracterizará por um tom de acirrada polêmica que levará à formação de duas facções opostas, as quais se agruparam contra e a favor das atividades do grupo Guignard (Zílio, 1983, p. 43). O confronto transcende a mera rivalidade. Com a presença de Guignard, trava-se uma clara luta político-ideológica no campo artístico, que toma a forma específica do embate entre modelos pedagógicos e estéticos: aos clichês, aos modelos ideais, às formas rígidas de ensino do academicismo, a nova escola vai contrapor o "liberalismo didático", o método modernista do ensino livre; às formas perceptivas próprias do academicismo, que valorizava a pintura figurativa do real, o modernismo de Guignard privilegiará a interpretação da realidade (Barbosa de Oliveira, 2002). O mestre procurava intensificar a sensibilidade artística dos alunos e aguçar também a visão crítica da relação passado-presente, abrindo a possibilidade de novos caminhos para relacionar o tradicional ao moderno, não para a cópia do passado, mas para transcender o conflito (Andrés Ribeiro e Silva, 1997 p. 194). Guignard dá o exemplo aos seus alunos, revolucionando as antigas percepções das paisagens mineiras.

\section{A obra de Guignard: as paisagens imaginantes}

Os principais temas pictóricos tratados por Guignard ao longo de sua obra foram: os retratos, as naturezas-mortas, as flores, o sagrado e as paisagens. A convergência de inúmeros elementos em suas telas tem sido apontada como característica de sua pintura, convergência que alcança o mais alto e complexo grau nas paisagens que Guignard pintou na maturidade e que denominou imaginantes. ${ }^{7}$

Sem dúvida, a natureza tem sido o elemento predominante em toda sua obra pictórica. Mas, assim como ao longo da própria história da arte a evolução da paisagem marca as várias fases da nossa concepção da natureza, em Guignard, há um aprofundamento gradual do tema. Considerando apenas as paisagens brasileiras pintadas por Guignard, podem ser apontadas três fases em sua produção: a tropical (1936-40), representada pelas pinturas sobre o Jardim Botânico do Rio de Janeiro (Figura 1); Itatiaia (1940-42), quando o artista se interessa mais pela paisagem natural e os espaços amplos (Figura 2), e, por último, a paisagem mineira (1944-1962) (Figuras 3, 4 e 5) (Morais, 1979, p. 80 e ss.). Na fase tropical, tratou o Jardim Botânico do Rio de Janeiro realisticamente nos vários trabalhos que realizou e também buscou simbolizar a paisagem tropical brasileira; nas pinturas da serra de Itatiaia, Guignard tem a precisão de um topógrafo, resultado de uma observação demorada. Mas é em Minas Gerais que vai realizar a obra paisagística mais significativa de sua carreira, aquela que a crítica considera representativa de sua maturidade artística.

É consenso entre os críticos que sua melhor expressão artística é essa recriação da geografia e do espírito da Minas colonial, de Ouro Preto, Sabará, Diamantina e Mariana. Na fase mineira, o pintor criou uma arte rica e densamente carregada dos valores espirituais de Minas Gerais fixados nas cenas, nos retratos, na via-sacra, na cabeça de Cristo, nas naturezas-mortas, mas especialmente nas paisagens, o tema mais significativo e mais amplamente trabalhado pelo artista (Sampaio, 1977, p. 27). ${ }^{8}$

$\overline{\text { 7. Acertadamente, }}$ tem sido apontado que praticamente todos os principais "temas" tratados por Guignard estão indicados numa tela denominada Os noivos (1937). São eles o retrato, a paisagem, as flores e o sagrado. Apenas a natureza-morta estaria ausente neste "arquiquadro", síntese de tantos elementos, sendo o principal deles a convergência da cultura das elites e a do povo comum. Essa convergência haverá de se dar inúmeras vezes ao longo de seu percurso de artista e atingirá seu mais alto e complexo grau nas "paisagens imaginantes" (Coelho Frota, 1997, p. 57)

8. Diz Ferreira Gullar: "Sua fixação em Minas Gerais, concorrendo para a fixação de uma temática em sua obra, deu a essa mesma obra uma qualidade adicional às qualidades propriamente estéticas: a identificação com um mundo cultural característico, com uma realidade regional que, invertendose os termos da relação, continua agora com o suporte da linguagem que a revelou pictoricamente. A pintura de Guignard e a paisagem mineira são hoje uma coisa só, completando-se" (grifo nosso, apud Sampaio, 1977, p. 24). 


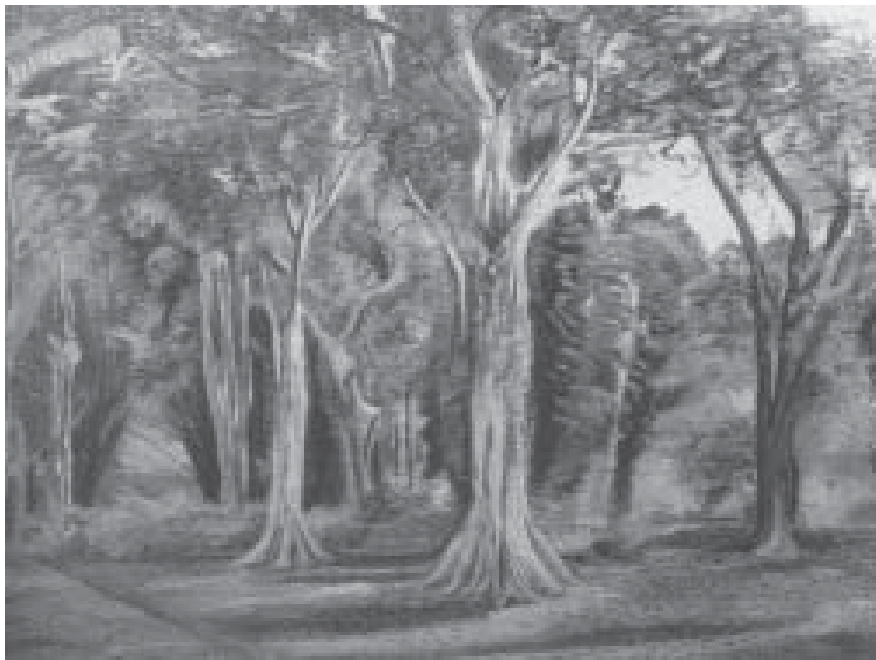

Figura 1 - Jardim Botânico, 1938

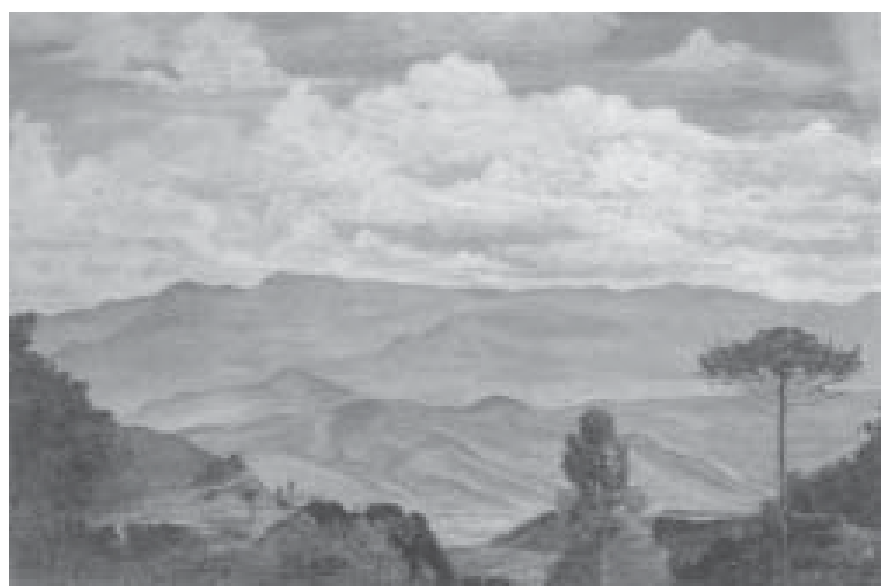

Figura 2 - Paisagem de Itatia, 1940

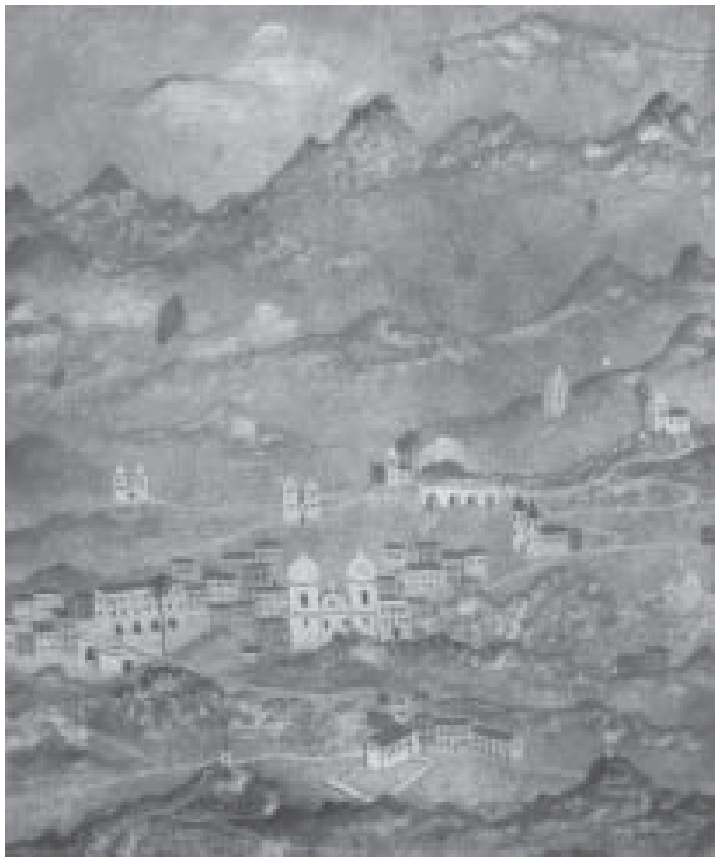

Figura 3 - Paisagem imaginária, 1952

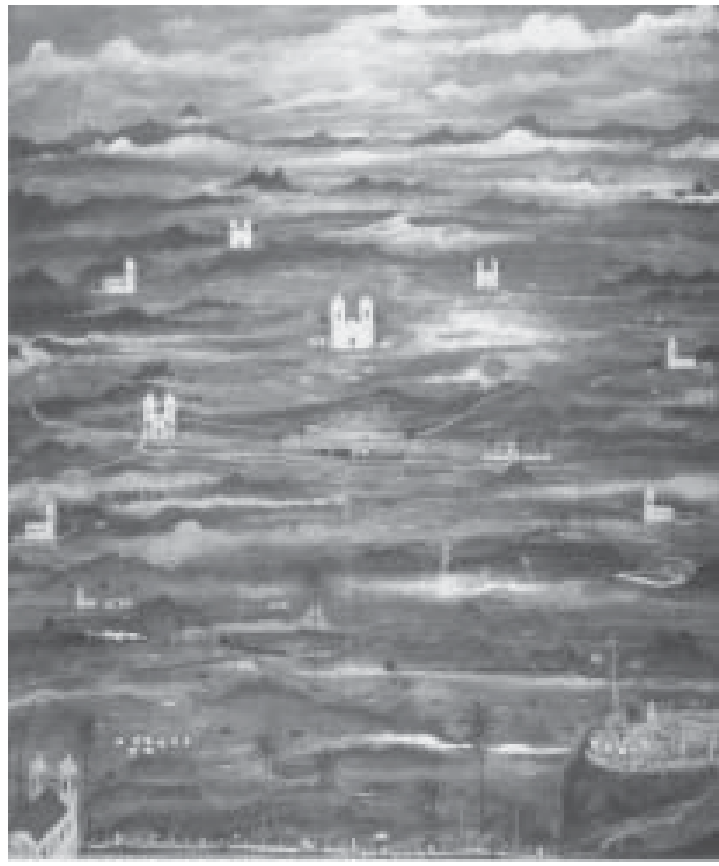

Figura 4 - Fantasia de Minas, 1955

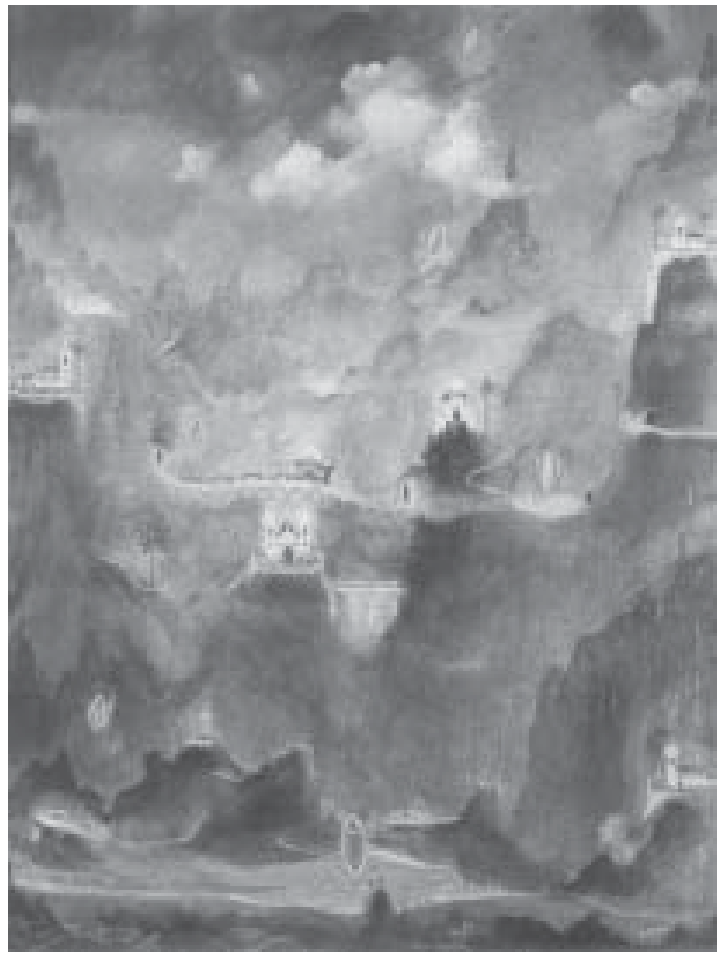

Figura 5 - Paisagem imaginante, 1961

De início, as paisagens mineiras se caracterizavam pelo realismo ou pela veracidade topográfica - o que se via na tela podia ser comprovado no modelo (Figuras 1 e 2). Nos últimos anos, manifesta-se uma vontade de despojamento, com evidente intenção construtiva, e até de livre fantasia. A paisagem perde a materialidade, 
o desenho ágil e a pincelada livre dão lugar a uma representação pictórica que se situa a meio termo entre a figuração do real e a expressão do imaginário. São suas Fantasias de Minas Gerais (Figuras 3, 4, e 5). Essas "fantasias", de atmosfera onírica e luminosa, surgem como síntese dessa paisagem com a qual Guignard conviveu tanto tempo, a ponto de fundir num único espaço várias cidades e a cultura regional, de fazer convergir nesses espaços fundidos os extremos da cultura local, do refinamento das elites às manifestações populares. A verticalidade da composição permite a superposição, no tempo e no espaço, de situações e eventos, da topografia e da arquitetura já tornada memória, acentuando desse modo o caráter fantasioso da proposta (Sampaio, 1977, p. 25). ${ }^{9}$

É erro acreditar que a arte tem na natureza o seu protótipo. Paul Klee já dizia que "a arte não reproduz o visível, ela o torna visível”. Para a arte, a natureza não passa de matéria sem forma intrínseca. Ao contrário, a nossa idéia da natureza conforma-se à arte, pois foi moldada por grandes artistas (apud Tavares, 1998). Assim, a paisagem mineira foi objeto de múltiplas interpretações pictóricas ao longo do tempo: do realismo das mais antigas que, com intenção de documentar a originalidade do território, cunharam um discurso visual próximo ao da narrativa histórica, às leituras mais simbólicas, cuja expressão mais acabada se encontra em Guignard e seus discípulos. Suas interpretações pictóricas se afastaram cada vez mais da realidade topográfica que representavam, para dar lugar à representação imaginária da paisagem local, fantasias muito reveladoras da natureza mineira que, em certo sentido, hoje constituem a paisagem do imaginário social. Enquanto muitos artistas permanecem fiéis à antiga forma

\footnotetext{
9. Diz também Frederico Morais: "a paisagem em Guignard é mais do que tema. É personagem. Ela é” (Morais, 1974, p. 24). Marília Andrés Ribeiro e Fernando P. Silva (1997), em alentada e cuidadosa avaliação das artes plásticas neste último século em Belo Horizonte, sintetizam bem o significado da presença de Guignard em Minas Gerais: "O liberalismo didático é acentuado nessa primeira fase de atuação de Guignard. A paisagem, o desenho, a linguagem lírica e as cores livres compõem um discurso mineiro. Apaixonado pelas montanhas e pelas cidades históricas, numa leitura lírica do universo barroco, o artista recria a paisagem colonial com igrejas e casarios que dançam em meio ao espaço pictórico" (p. 194, grifo nosso).
}

de conceber a paisagem, a invenção abriu novas perspectivas, permitindo o exercício da reescritura da montanha e da história de Minas, permanecendo a paisagem como ponto principal de referência da arte mineira das últimas décadas. Com efeito, a morte de Guignard, em 1962 (Figura 6), não marcou o fim de uma era. Muitos de seus alunos o substituíram, mantendo vivos seus ensinamentos. Muitos artistas permanecem fiéis à paisagem de Minas segundo a linguagem e os esquemas mais ou menos próximos de Guignard. $^{10}$

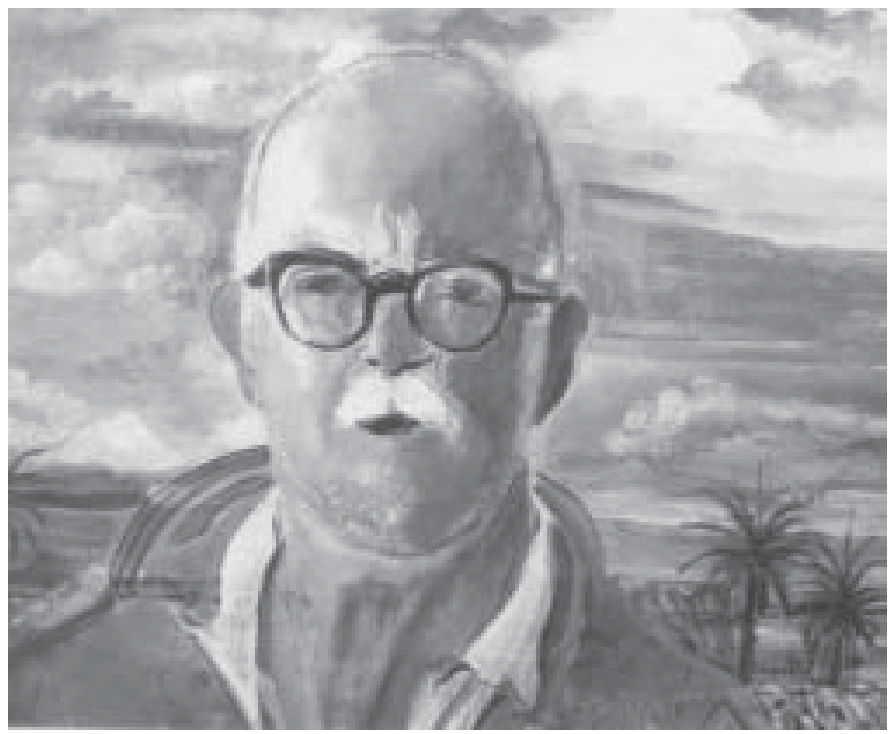

Figura 6 _Auto-retrato, 1961

\section{Análise simbólica das paisagens imaginá- rias de Guignard}

O sentido de uma obra, literária ou pictórica, segundo Durand (1993), não se pode reduzir às estruturas psicológicas de seu autor, à sua biografia, como ensaiaram alguns psicanalistas,

10. A década de 1950 marca o início de uma nova etapa econômica para Minas Gerais e, conseqüentemente, também para o mundo das artes e das letras. Em Juiz de Fora, o Núcleo Antônio Parreiras desempenha o mesmo papel renovador que teve a escola Guignard em Belo Horizonte. Dele participaram artistas como Inimá de Paula, Edson Motta, Nívea Bracher, Roberto Gil, Roberto Vieira e Carlos Bracher, todos interessados em manipular os elementos da paisagem. A efervescência artística continua nos anos 60 e conta entre seus principais impulsores os irmãos Bracher. Ouro Preto, por seu lado, retoma nos anos 60 seu prestígio de centro cultural, que teve em Estevão Souza um sucessor de Guignard, um continuador da obra paisagística do seu mestre. Em outras cidades mineiras, vão se formando grupos de artistas, com uma produção que se faz hoje relevante (Sampaio, 1977, p. 30). 
nem exclusivamente aos dados sociais e históricos, como defende alguma sociologia da arte, nem mesmo ao sistema mecânico de formas - disposição sintática de um discurso que não diz nada -, como quer certo estruturalismo.

Ao rejeitar as alternativas reducionistas que tornam a obra de arte um mero epifenômeno, acessório cujo sentido se busca num ser psíquico, social ou existencial mais profundo, se faz necessário dar a primazia à própria obra, a sua singularidade criadora, por cima de todas as formalizações. Evitaremos, então, partir de qualquer ordem de estruturas preestabelecidas alheias à obra, pois entendemos que é ela que cria estruturas e formas, sejam harmônicas ou contrárias e conflituosas (Garagalza, 1990, p. 134).

Tratar-se-á de compreender a articulação da obra de arte com o imaginário, não como simples "visão de mundo", mas como universo que ordena e articula valores de origem mítica, pois a autêntica obra de arte, segundo ensina Durand (1993), é aquela que consegue ressuscitar ou restaurar o mito. Assim, o conhecimento de uma obra requer seguir as tensões estruturais que a constituem. Toda obra de arte, especificamente a pintura, apresenta, segundo Durand, dupla cara: é criação original, singular (schopfung), mas também, antagonicamente, se situa numa rede significativa e estrutural já existente (gestaltung), o que suscita a compreensão, a interpretação, a familiaridade (1993, p.129-130). Portanto, só se entende a obra por meio de uma rede de estruturas heterogêneas, díspares e por vezes antagônicas que só ela unifica com a sua unicidade. A tensão estrutural é a essência da obra. O conhecimento adequado dela radica, assim, na compreensão da tensão entre a originalidade criativa e a posição ocupada numa rede de significação.

Numa primeira aproximação, é preciso resistir à tentação biográfica, de atribuir à vida trágica, boêmia e solitária de Guignard, por exemplo, o sentido de sua pintura. Quando atentamos para a temática mais característica e longamente explorada de sua obra, a paisagem mineira, não há dúvida de que estamos diante de uma temática herdada. O tema, de recorrência obsessiva, é evidentemente o mais complexo de sua produção artística. Colocada contra o fundo dos demais discursos paisagísticos regionais, pictóricos ou não, é inegável que nos defrontamos com um verdadeiro mitema, no sentido que Lévi-Strauss dá a esse termo (LéviStrauss, 1968, p. 186 e ss.), um tema recorrente que atravessa o imaginário regional ao longo do tempo e de suas várias manifestações estéticas.

Se a paisagem mineira, a psicologia de seus homens e sua cultura foram intensamente figuradas pela literatura e pela pintura de várias gerações, o mitema alcança, na obra de Guignard, sua mais complexa e livre expressão visual, verdadeira síntese imagética dos inúmeros olhares que contribuíram para a construção desse imaginário regional desde os tempos coloniais.

São as imagens da paisagem, de seus homens e de sua cultura, sobrecarregadas pelos investimentos figurativos de capas imaginárias de muitas gerações que ele sintetiza em suas paisagens imaginantes. A paisagem mineira, na suas Fantasias de Minas, constitui uma temática tão onipresente na obra madura de Guignard que toma valor de arquétipo, porque o que se epifaniza na suas imagens poéticas e quase oníricas não é um discurso conceitual qualquer sobre a região, visão de mundo, mas uma temática que evolui para um modelo imaginário, para o arquétipo (Durand, 1993, p. 145-146). Efetivamente, a paisagem, descrita e inventada por sua pintura, tornou-se a paisagem regional por excelência. O objeto, revelado, construído e inventado pela atividade pictórica, acabou por transformar-se, pela sua visão poética e lírica do espaço, no suporte figurativo de todo um regionalismo que se encontrava em vias de transformação. ${ }^{11}$

Se história e ideologia não são suficientes para constituir uma obra pictórica, permitem compreender melhor seu acento temático. A obra de Guignard é muito mais. Se não podemos reduzi-la às coordenadas sociais e culturais, do meio e momento que a viram nascer, sua obra

\footnotetext{
11. Junto da forte renovação modernista experimentada pela pintura local, a literatura mineira viu aparecer, por exemplo, o melhor da obra de Guimarães Rosa: Grande sertão: veredas (1956), expressão exemplar na construção de um regionalismo transfigurado que, tomando o sertão, espaço exterior, como sua matéria, converteu-o em espaço interior: "o sertão é dentro da gente", dizia Guimarães Rosa (Franco Carvalhal, 2001).
} 
apresenta-se como expressão de um momento de grande tensão no campo da arte, protagonizado pelo academicismo conservador e pela renovação modernista. ${ }^{12}$

Só se entende uma obra, diz Durand, através de uma rede de estruturas heterogêneas, díspares e por vezes antagônicas que só ela unifica com a sua unicidade. A famosa compreensão é a tomada de consciência do conflito, das disjunções explicativas no seio do ato criador. Quando se reduzem as contradições, não se "compreende"; entretanto, há compreensão quando se situam e admitem essas contradições no universo que suportam com a sua tensão antagônica. Assim considerada, a pintura paisagística arquetipal de Guignard apresenta-se como configuração única de um paradoxo, aquele que abriga a intensa contradição entre passado e presente que ele presencia e vivencia sob a forma da acirrada luta política que travam conservadores e modernos, embate entre os mundos da tradição e da modernidade, que no terreno artístico confronta, em matéria de sensibilidade estética, ortodoxos e heterodoxos: a tradição classicista, de um lado, e a heresia modernista, de outro. Certamente, a temática paisagística tão presente em sua obra, que acompanha as questões de seu tempo e região, é sem dúvida parte da herança artística local, mas a forma original de representar essa paisagem, concebida por Guignard, estabelece uma tensão estrutural entre a temática da paisagem mineira, por um lado, e o estilo pictórico modernista, por outro. Este último, em síntese própria e meticulosa das correntes expressionista, cubista e surrealista, experimenta, remodela, recria, inventa e fantasia as imagens arquetípicas da tradição cultural, a paisagem montanhosa, o casario colonial das cidades do ouro e do diamante, enfim, o cenário do passado mítico dos heróis nacionais. Em suma, com imaginação e novo estilo pictórico, altera profundamente, porém não abole a ordem tradicional.

12. Essa tensão toma a forma de uma luta propriamente estética entre as tendências do academicismo conservador, de um lado, e a renovação modernista, de outro, confronto vivenciado nos grandes centros produtores no Brasil desde os anos 20, como São Paulo e Rio de Janeiro, e que se reproduz tardiamente em Belo Horizonte nos anos 40, luta propriamente artística da qual Guignard foi protagonista principal, como produtor e também diretor de uma escola criada com esse fim.
Sem abandonar a idéia de que a pintura é do plano da imitação, do redobramento realista, o artista deu as costas ao real, como fez Cézanne - a quem toma por modelo em suas paisagens sobre a serra do Itatiaia -, para dar-lhe uma nova visibilidade, uma visibilidade específica. Guignard simplesmente substituiu o mundo visível pelo universo esquizóide de sua pintura. Nele, mais que fantasia há uma total desconsideração pela realidade: a perspectiva e a proporção, o absurdo das figuras e situações, o alheamento total aparecem como autênticas transgressões desse mundo que toma por referência. Mas a sensação de irrealidade, como se sabe, é um dos elementos específicos da modernidade (Zílio, 1983, p. 11).

Mais ainda, na tensão estrutural que constrói entre temática social x estilo singular, sua linguagem colorista e decorativa é poderosamente reforçada pelo regime diurno da imagem (Durand, 1989). Pela irradiação de uma luminosidade que dói nos olhos, mas empresta à pintura uma vida maior - como o próprio Guignard chega a declarar-, sua pintura desenha um espaço aberto e provoca um efeito de transporte em que o olhar do espectador é levado a subir. Nas paisagens expressionistas pintadas na fase Itatiaia, o painel é tomado de matéria abstrata, céu e nuvens, céu tingido de azul, céus nublados, límpidos, de azuis frios, contra horizontes profundos que criam grandes ilusões de espaço. Na fase mineira mais avançada, a tela vai esfriando, a pincelada flui, há casas cinzentas riscadas de terra, tons sujos, tons frios, céu vasto, aberto, que ocupa grande parte da tela, céu pesado de densa matéria vaporosa, nada de azul, tudo cinza, com toques de roxo, de vermelho, e de verde sujo, produzindo o colorido exato de um espaço desmaterializante, marcado por montanhas emergentes, balões e igrejas, oferecendo uma concepção aérea da paisagem mineira. Os elementos, como casas, igrejas, palmeiras, fábricas, têm quaisquer tamanhos, emergindo da neblina sem compromisso com a perspectiva (Coelho Frota, 1997).

De acordo com o esquematismo transcendental de Durand, as imagens do regime diurno estão dirigidas pela dominante postural, pelos grandes esquemas ascencional e distinguidor (diairético), e representados, entre outros, pelos 
arquétipos da luz e do ar. A conquista da posição vertical no homem, lembra Durand, possibilita a faculdade de separar, de discernir a distância pela vista. Regime marcado pela distinção e pela análise, utiliza-se da "antítese" como retórica fundamental que estabelece uma interpretação dualista baseada no jogo de figuras e de imagens antagônicas (Garagalza, 1990, p. 74). Não é difícil reconhecer essa estrutura da imagem nas paisagens fantasiadas de Guignard: a composição fortemente vertical, inundada de luz e ar em atmosfera carregada de nuvens, cujo caráter ascencional está simbolizado pelos esguios coqueiros, os destacados campanários barrocos e, principalmente, os balões coloridos de São João, eleva o olhar do espectador. A linguagem antitética de sua retórica pictórica manifesta-se na oposição dominante da composição, a que se constitui entre a figura e o fundo da pintura, jogo de contraponto que travam o casario colonial, medieval, o assentamento humano miniaturizado, de um lado, e o vasto cenário natural das cadeias montanhosas recortadas num agigantado espaço que domina a tela, de outro.

A imaginação diurna adota a atitude heróica da luta contra a "tentação" e exagera o aspecto maléfico de chronos. A ameaça da temporalidade e, portanto, da morte é afrontada por esse regime com a atitude distinguidora, que extrai e separa os aspectos positivos e os projeta num além atemporal (Garagalza, 1990, p. 74). Diante do monstro devorador, das trevas, que simbolizam o Tempo, o artista contrapõe os símbolos luminosos; diante da ameaça da queda, o esquema ascencional. A temporalidade combatida pelos símbolos luminosos, reforçados pelo esquema vertical e ascencional das paisagens, não deixa dúvida de que se trata do peso do passado colonial, representado pelo casario e pelas igrejas barrocas gulliverizados, miniaturizados - inequívoca representação arquetípica do regime noturno -, tudo sufocado por imenso espaço iluminado e atemporal.

Sobre a dinâmica própria do regime diurno da imagem, Gilbert Durand fala de quatro estruturas esquizomorfas. A primeira consiste no retrocesso autístico, manifesto na perda de "contato" com a realidade; a segunda, prolongamento lógico da anterior, manifesta-se na desa- gregação da representação do conjunto; a terceira, no geometrismo que se expressa na importância que adquire a simetria, a planificação e a lógica formal: o espaço e o assentamento geométrico são sobrevalorizados, agigantados. A quarta, por fim, é representada pelo modo de pensar que funciona por "antítese": todo o sentido do regime diurno do imaginário está pensado contra o semantismo das trevas, da animalidade, da queda, contra chronos, o tempo mortal.

A dinâmica esquizomorfa do imaginário não parece estranha à obra pictórica que analisamos: o retrocesso autístico e a desagregação, postos de manifesto na explícita desmaterialização produzida pela desconsideração transgressora do real, bem como a sobrevalorização do espaço, expressa pela monumentalidade montanhosa e o agigantamento do espaço, são indicadores claros do geometrismo da estrutura. Além disso, o pensar antitético que orienta todo o sentido da composição pictórica, do diurno contra o tempo mortal do passado ameaçador e tenebroso, é representado, na obra de Guignard, pela arquitetura colonial miniaturizada em face da cegante claridade do espaço agigantado e colorido que busca dominá-lo. O regime diurno da imagem valoriza a elevação e a altura porque são formas hiperbólicas, hipérbole generalizada: o alto, o grande, o veloz adquirem sempre valorizações positivas, desvalorizando, em conseqüência, o pequeno e o estático.

A estrutura antitética central que organiza as "paisagens imaginantes" guignardianas, resultado da polaridade que institui o desenho, nada mais é que a tradição e a modernidade, representadas pelo antagonismo que travam a temática social da paisagem, ancorada no passado mítico regional, e a destacada singularidade do estilo pictórico moderno de Guignard. Essa estrutura antitética nuclear recebe ainda o reforço de outras polarizações que acentuam a tensão e o sentido do regime diurno da imagem, como a que resulta do caráter estático da paisagem natural e da arquitetura, diante do ritmo e do movimento dos balões coloridos que cruzam todo o céu. A polaridade, objetiva e visual, entre as formas estáticas e dinâmicas de elementos pictóricos é robustecida pela antítese cromática que suportam as cores frias da natu- 
reza, do céu e das montanhas, dominantes no painel, e as cores quentes das construções e dos balões que integram a paisagem humana, de maneira que a cor, ao mesmo tempo, ordena e rompe o equilíbrio que finge realizar (Baudinet, 1976, p. 10). Pode-se assinalar, ainda, um último antagonismo estilístico entre o desenho de aparência primitiva, ingênuo, até infantil, e o traço elaborado que recusa a imitação da forma visível para transcendê-la. Esse dualismo reforça o antagonismo nuclear entre o tema e o estilo, que organiza toda a composição.

A análise estrutural em profundidade revela a dialética entre a estrutura do tema, a paisagem, e a estrutura dos regímenes profundos da imagem, apoiados pelo estilo pictórico. Poder-se-ia dizer que as estruturas estéticas - tema $x$ estilo / figura $x$ fundo -, bem como as polarizações cromáticas se opõem às estruturas morais $\mathrm{e}$ conceituais - passado $x$ presente / tradição $x$ modernidade -, resultantes da configuração de séries antagônicas. A vontade moralizadora do tema, representado pela visão modernista, fica desmentida pelo deleite perante o mundo que representa, espécie de consentimento à imagem nuclear: o passado mítico e tradicional da paisagem mineira (Durand, 1993, p.144).

O dualismo ético que anima a obra pictórica, expresso pela fórmula "tradição e modernidade", fica contestado: o que era crítica converte-se em aceitação. A paisagem colonial, tema conservador dos discursos regionais, elemento simbólico fundamental do mito da mineiridade, apresenta-se como objeto obsessivo de uma sensibilidade moderna que, em sua dualidade, pretende ser crítica do academicismo, da velha percepção, mas, paradoxalmente, a intenção renovadora dá lugar ao convite conciliatório da dualidade, ao reencontro entre tradição e modernidade, constituindo assim um grande oxímoro pictórico (Durand, 1993, p.144).

Uma obra humana não propõe um sistema de imbricação de classes ou relações unívocas: quando tomo consciência da disjunção das formas e de seus materiais [...], quando tomo consciência da obra enquanto configuração única do díspar, então sim compreendo essa obra, me aproximo mais a sua poética singular e a assimilo. A compreensão - o entendeu Weber com profundidade - passa pela aceita- ção do paradoxo [...], não há mais verdadeira estrutura que a que constrói, ou seja, que reúne numa obra única e viva, conflituosa, paradoxal, formas e materiais díspares. (Durand, 1993, p. 70)

Desaparece assim a possibilidade de uma hipotética novidade absoluta, como criação $e x$ nihilo: a autêntica obra de arte é sempre recriação, recorrência, ressurreição do mito.

\begin{abstract}
The landscape is a way of nature representation; is a cultural image of a geographic environment. As spatial symbol of a social imaginary, the landscape points out to a meaning, more than to the environment itself. In the case studied, the literature and plastic arts, have been essential to build the representations of regional space and for the elaboration of the greatest mythical images. This representation system has the landscape as dominant symbol and constitutes the basis of a regional ideology as much as the self-image of its inhabitants. In this paper, we try to for understand the meaning of the modern artistic production of Alberto da Veiga Guignard. We focalize his Minas Gerais regional landscape painting, not as a simple "cosmovision" but as a plastic universe articulated with the social imaginary, been simultaneously a renovator and an organizer of mythical values, because the genuine work of art is the one that revive or restore the myth.
\end{abstract}

Key-words: art and imaginary; landscape, art and identity; regional identity, landscape and simbolism.

\section{Referências}

ANDRADE, Mario. In: Diário Nacional de São Paulo. 9/4/1929.

ANDRÉS RIBEIRO, Marília e SILVA, Fernando P. da. Um século de história das artes plásticas em Belo Horizonte. Belo Horizonte: Fundação João Pinheiro, C/Arte, 1997.

BAUDINET, Marie-José. Invisibilidad de la pintura. Revue d'Esthétique, n. 1.1976-C.N.R.S. Versión castellana: la práctica de la pintura. Barcelona: Gustavo Gilli, 1976.

BARBOSA DE OLIVEIRA, Frederico C. Lutas no campo artístico em Minas (1944-1962): Guignard e o modernismo. Belo Horizonte, 2002. Monografia (Graduação em Ciências Sociais) - UFMG.

BENDER, B. Landscape: politics and perspectives. Oxford: Berg, 1995.

COELHO FROTA, Lélia. Guignard: arte e vida. Rio de Janeiro: Campos Gerais, 1997. 
COSGROVE, D. \& S. DANIELS. The iconography of landscape. Cambridge: Cambridge Univ. Press, 1997. DURAND, Gilbert. A imaginação simbólica. São Paulo: Cultrix, 1988.

. As estruturas antropológicas do imaginário. Lisboa: Presença, 1989.

De la mitocrítica al mitoanálisis: figuras míticas y aspectos de la obra. Barcelona: Anthropos; México: Universidad Autónoma MetropolitanaIztapalapa, 1993.

FELDMAN-BIANCO, B. \& M. L. MOREIRA LEITE. Desafios da imagem. São Paulo: Papirus, 1998.

FÍGOLI, Leonardo. Verbete "Paisaje". Diccionario de la existência. In: A. ORTIZ-OSÉS, P. Lanceros et alli. (Org.). Barcelona: Anthropos, 2006.

FRANCO CARVALHAL, Tânia. Recepção produtiva no Sul. Jornal Estado de Minas/Pensar 23/06/2001.

GARAGALZA, Luis. La interpretación de los símbolos: hermenêutica y lenguaje en la filosofía actual. Barcelona: Anthropos, 1990.

HOBSBAWM, E. A invenção das tradições. Rio de Janeiro: Paz e Terra, 1997.

LÉVI-STRAUSS, Claude. Antropología estructural. Buenos Aires: Eudeba. 1968.

LIMA, Alceu Amoroso. Voz de Minas: ensaio de sociologia regional brasileira. Rio de Janeiro: Agir, 1945.
LOBATO CORRÊA R. e Z. ROSENDAHL. (Org,) Paisagem, tempo e cultura. Rio de Janeiro: UERJ, 1998.

MORAIS, Frederico. Guignard. São Paulo: Gráfica Impressores, 1974.

MOREIRALEITE, M. L. Texto visual e texto verbal. In: FELDMAN-BIANCO, B. \& M.L.MOREIRA LEITE (Org.) Desafios da imagem. São Paulo: Papirus, 1998.

PORTO ALEGRE, M. S. Reflexões sobre iconografia etnográfica: por uma hermenêutica visual. In: FELDMAN-BIANCO, B. \& M.L.MOREIRA LEITE (Org.) Desafios da imagem. São Paulo: Papirus, 1998 REYNOLDS, Donald M. Introducción a la historia del arte. Barcelona: Gustavo Gili, 1985.

SAMPAIO, Márcio. A paisagem mineira. Belo Horizonte: Fundação Palácio das Artes, 1977.

SCHAMA, Simon. Paisagem e memória. São Paulo: Companhia das Letras, 1996.

TAVARES de Araújo, Olívio. In: Jornal Estado de Minas/Pensar, 8/8/1998.

TILLEY, C. A phenomenology of landscape. Oxford: Berg, 1994.

VIEIRA, Ivone Luzia. A Escola Guignard: a cultura modernista em Minas 1944-1962. São Paulo: Cia. Empreendimentos Sabará, 1988.

ZÍLIO, Carlos et al. A modernidade em Guignard. Rio de Janeiro: PUC-RJ/Lis Gráfica editora,1983. 